\title{
REESTRUTURAÇÃO DO CAPITAL E INDÚSTRIA CALÇADISTA NA REGIÃO DO CARIRI - CE
}

\section{Restructuring of the Capital and Footwear Industry in Cariri Region, Ceará State}

\author{
Fábio Ricardo Silva BESERRA ${ }^{1}$
}

\begin{abstract}
RESUMO
A indústria de calçados na Região do Cariri é hoje uma das mais importantes do Estado do Ceará. Nos últimos 20 (vinte) anos, este segmento vem sofrendo uma sensível expansão associada a uma série de transformações. $\mathrm{O}$ artigo enfoca as novas configurações territoriais da Região, produto desse desenvolvimento industrial e da dinâmica do capital global. Essas metamorfoses associam-se a um outro conjunto de mudanças no plano político-econômico estadual, nacional e mundial que estão intimamente relacionados. A análise se propõe crítica e tem como perspectiva entender a indústria enquanto atividade produtiva, capaz de transformar o conteúdo do espaço geográfico. Este espaço é visto não como um palco da atividade humana, mas como uma produção histórica e social, condição e meio de toda a atividade humana.
\end{abstract}

Palavras-chave: Industrialização; Reestruturação do Capital; Cariri Cearense.

\begin{abstract}
Nowadays footwear (shoes) industry of Cariri region is one of the most important industries of Ceará State. In the last 20 years, as a consequence of several transformations of the place, this industry branch has been expanding a lot. This article focuses at the new territorial transformations showed in the region, as a product of this industrial development and the global capital dynamic. These metamorphosies are associated with another set of changes in the politic-economical plan of the state, country and the world which they are closely related to. This present analysis is purposively critic and intends to understand the industry as a productive activity which is able to transform the geographic space content. This space is not seen as a stage of human activity, but as a historical and social production, condition and means of all human activity.
\end{abstract}

Keywords: Industrialization; Capital Restructuring; Cariri Cearense. 
BESERRA, F. R. S. Reestruturação do Capital e Indústria Calçadista na Região...

\section{INTRODUÇÃO}

A indústria calçadista do Cariri é, nos dias atuais, uma das que mais contribui para manter o estado do Ceará entre os três maiores produtores do ramo no país. Esta indústria, nascida a partir da segunda metade do século XIX em moldes artesanais e utilizando o couro como matéria-prima principal, vem sofrendo, nos últimos 20 (vinte) anos, uma sensível expansão associada a uma série de transformações. Estas vão desde a entrada de materiais sintéticos na composição do calçado, substituindo o couro por outras matériasprimas, até o reordenamento do chão da fábrica, com a reestruturação do processo produtivo propriamente dito e a inclusão de novas máquinas e novos meios de controle do trabalho.

Concomitantemente, nesse período, a Região passa por um reordenamento territorial cuja lógica é a do mercado, sendo a orientação o crescimento da indústria e do consumo. Dessa forma, as indústrias de

\section{UMA NOVA FASE NA ORGANIZAÇÃO POLÍTICA E ECONÔMICA DO CEARÁ}

O ano de 1986 é relevante no quadro políticoeconômico cearense. Naquele ano, Tasso Jereissati era eleito governador do Estado em disputa contra Adauto Bezerra, então vice-governador e um dos três coronéis que dividiam o domínio da política cearense desde $1964^{2}$.

Assentado sobre um discurso mudancista, em que responsabilizava o "domínio dos coronéis" pelo atraso do estado frente ao país, Jereissati afirmava a necessidade da tomada de uma "consciência racional" para o desenvolvimento de um "projeto civilizatório" para o Ceará. Somente por meio desse projeto seriam possibilitados a modernização e o desenvolvimento do Estado (TEIXEIRA, 1995).

Esse discurso representava não somente a figura do novo governador, mas também a do grupo no qual ele estava inserido e que o apoiara para a chegada ao poder político do estado. Estamos nos referindo ao grupo que, nos finais de 1978, assume o Centro Industrial do Ceará calçados alcançam novos mercados, quer nacionais, quer internacionais, expandindo sua produção e fazendo da Região e do Estado um polo produtor e um mercado competitivo da produção mundial.

A essas metamorfoses, que se dão especificamente no âmbito da produção e da circulação, associa-se um outro conjunto de mudanças no plano político-econômico estadual, nacional e mundial que estão intimamente relacionados.

A análise se propõe crítica e tem como perspectiva entender a indústria enquanto atividade produtiva, capaz de transformar o conteúdo do espaço geográfico. Este espaço é visto não como um palco da atividade humana, mas como uma produção histórica e social, condição e meio de toda a atividade humana. Este espaço é produto das relações alicerçadas na divisão do trabalho, vigente no sistema sociometábolico do capital.
(CIC) e desencadeia a esfera política estadual.

O CIC foi criado em 1919, objetivando reunir os proprietários de estabelecimentos fabris do Ceará para tratar de assuntos de seu interesse comum e estudar as possibilidades de novos empreendimentos na busca de desenvolvimento do estado. Ao final dos anos 1950 a presidência da entidade é atrelada à da Federação das Indústrias do Estado do Ceará (FIEC), permanecendo assim até o ano de 1978, quando seria novamente emancipada. Em 2009 completa seus 90 anos de existência e atua continuamente no desenvolvimento da atividade industrial do Estado.

Ao assumir o poder, Tasso Jereissati passa então a adotar uma série de medidas na busca de efetivar o seu discurso. As primeiras dizem respeito ao saneamento da máquina estatal. Foram desenvolvidas políticas de contenção de despesas rigorosas, o enxugamento do quadro de pessoal e o saneamento do Banco do Estado do Ceará $(\mathrm{BEC})^{3}$. Com isso, objetivava-se a reforma do

2 Eram os três coronéis: Virgílio Távora, Adauto Bezerra e César Cals.

3 Após conseguir alcançar seus objetivos conquanto ao BEC, a "era mudancista", agora representada pelo Governo Lúcio Alcântara efetivou a venda do Banco, no ano de 2006, para o Bradesco. A luta entre governo e funcionários desenvolvia-se desde o último governo Tasso Jereissati, mostrando a grande força e representatividade dos funcionários que, lamentavelmente, foram vencidos na luta contra o capital financeiro. 
BESERRA, F. R. S. Reestruturação do Capital e Indústria Calçadista na Região...

Estado, recuperando suas finanças e sua capacidade de investimentos. Com essas medidas iniciais foram criadas várias novas empresas no estado, enquanto outras continuariam se modernizando, calculando-se que os investimentos alcançariam a soma dos 220 milhões de dólares.

O contexto em que se insere a fase inicial do Governo das Mudanças, na conjuntura nacional, mostra-se favorável às práticas e ao discurso estabelecido pelo então governador. Após vinte anos de ditadura militar, os anos de 1980 foram marcados pela abertura política e pelo processo de redemocratização nacional. Naquele momento se formavam as bases para a abertura econômica que ocorreria na década seguinte.

Antes de prosseguirmos na trajetória dos "governos das mudanças", isto é, da permanência do grupo atrelado a Tasso Jereissati no comando do estado, consideramos necessário aprofundar um dos pontos marcantes do discurso do referido grupo, a diferenciação ou "ruptura" dos "jovens empresários" com os "coronéis" que governavam o Ceará desde a década de 1960.

Segundo análise feita por Teixeira (1995:8), "a era do $\mathrm{CIC}$ não representou um corte radical com o passado e sim uma intensificação do desenvolvimento da lógica de um processo de trabalho produtor de mercadorias". Ainda segundo este autor, é sob a tutela dos coronéis que as forças produtivas do estado são realmente revolucionadas.

Do ponto de vista material, é exatamente durante os governos dos "coronéis" que o Ceará recebe um aporte infraestrutural significativo, sobretudo nos governos de Virgílio Távora. Foram construídas rodovias que cortaram o território estadual, houve a chegada da energia de Paulo Afonso e a arrancada no processo de industrialização. Mais uma vez, são importantes as palavras de Teixeira (1995) ao afirmar que, "a partir dos anos sessenta, o Ceará se torna o terceiro maior absorvedor de recursos da SUDENE para o desenvolvimento industrial". É ainda com Virgilio Távora que se instala o Terceiro Polo Metal-Mecânico do Estado, bem como o sistema de telecomunicações e a universalização do Ensino Médio.

Do exposto, é possível concluir que as décadas de 1960 e 1970 foram permeadas por profundas alterações estruturais na economia cearense. Entretanto, embora os "coronéis" tenham promovido tais mudanças, estas não os pertenciam, mas sim, ao capital. De outro modo, a partir do momento em que os "coronéis" entram em choque com a acumulação do capital, com suas atitudes conservadoras e patriarcalistas, promovendo $o$ endividamento do estado e comprometendo seu desen- volvimento, eles se tornam um problema para o desenvolvimento do capital e precisam ser substituídos.

O grupo do CIC é, naquele momento, o elemento capaz de imprimir uma feição moderna e desenvolvimentista à máquina estatal, capaz de cumprir os pré-requisitos básicos de uma sociedade produtora de mercadorias. Recuperada a capacidade de financiamento do Estado e com a reestruturação do capital em curso, a economia cearense consegue superar a crise em que se encontrava.

Caberia ao sucessor de Tasso, Ciro Gomes, levar adiante este projeto de modernização da sociedade, tendo como preocupação central uma política de investimentos para o Estado.

A consolidação desses projetos vem com a retomada de Tasso Jereissati ao governo do estado em dois governos consecutivos (1995-2002) e com o seu "Programa de Promoção Industrial e Atração de Investimentos". O Programa objetivava desenvolver mecanismo para a divulgação de oportunidades de investimentos industriais através de incentivos fiscais e financeiros, apoio tecnológico, mercado e infraestrutura.

Quesito importante no programa é a interiorização da industrialização, ou melhor, a desconcentração espacial das indústrias na Região Metropolitana de Fortaleza (RMF). Assim, o Estado elegerá algumas microrregiões para receberem investimentos maciços e tornarem-se aptas a receberem novas unidades industriais ou modernizar para melhor produzir aquelas já existentes.

Com a chegada de Lúcio Alcântara ao Governo, a partir de 2003 , o projeto de industrialização continua como um dos principais de seu plano de governo, sofrendo alguns redirecionamentos que reafirmam a necessidade de industrialização do interior do Estado bem como o desenvolvimento das cadeias produtivas já existentes. Logo, é criado um novo órgão gestor da política industrial, a Secretaria de Desenvolvimento Local e Regional, com o intuito de potencializar o desenvolvimento de regiões dinâmicas do interior do estado.

Por fim, a partir dos anos de 1986 as ações do governo do estado, passam a ocorrer, sobretudo, mediante a parceria com o capital privado. Segundo Abu-El-Haj (1997), entre os aspectos mais importantes desse novo "desenvolvimentismo", sobressai a atuação marcante do Estado na tentativa de conduzir o ordenamento econômico local à lógica do mercado, orientando também o crescimento industrial e o mercado consumidor. O papel do Estado é, segundo Pereira Júnior (2005), o de fomentar a abertura de espaços para assegurar a consolidação do capital industrial do Ceará, como veremos a seguir. 


\section{A ABERTURA ECONÔMICA E A EXPANSÃO CAPITALISTA NO TERRITÓRIO CEARENSE}

Como já afirmamos, os anos 1980 foram marcados, no Brasil, pelo processo de redemocratização, pela abertura política enquanto desfecho da ditadura militar. Concomitantemente já se ensaiava naquela década a abertura econômica, na busca de tornar o país competitivo na mundialização do capital. No início da década de 1990 é eleito presidente Fernando Collor de Melo, o responsável pela efetivação desta abertura econômica e pelas adaptações necessárias para que houvesse uma adequação do Brasil às "regras do jogo" da economia internacional (ARAÚJO, 2000; DRUCK, 1999).

Essas adequações não ocorreram de forma autônoma, independente, mas seguiram diretrizes muito claras da comunidade financeira internacional (sobretudo o FMI e o BIRD). Buscou-se ajustar as economias dos países periféricos às novas demandas dos países centrais, ao processo de reestruturação do capital e à nova ordem do mercado no plano internacional. A essas diretrizes denominou-se Consenso de Washington.

Segundo Druck (1999), o Consenso de Washington contém uma essência econômica e um conteúdo político. Com relação a este último, os princípios básicos seriam a manutenção da democracia e o ajuste da estabilização com as políticas neoliberais. Conquanto à sua essência econômica, pode ser resumida em três objetivos básicos, a saber,

[...] a) estabilização da economia (corte no déficit público, combate à inflação), em geral, tendo por elemento central um processo, explícito ou não, de dolarização da economia e sobrevalorização das moedas nacionais; b) reformas estruturais com redução do Estado, através de um programa de privatizações, desregulação dos mercados e liberalização financeira e comercial; c) abertura da economia para atrair investimentos internacionais e retomada do crescimento econômico (DRUCK, 1999, p. 23).

Importante notar que, atrelado a esse conjunto de práticas e deliberações, está a ideia de globalização, isto é, a ideia de um movimento inelutável de integração econômica de escala mundial apoiado no desenvolvimento dos meios de comunicação e acoplado ao imperativo neoliberal, supostamente praticado pelos maiores centros de acumulação.

Na medida em que Collor proporciona a abertura econômica, diminuindo as barreiras não tarifárias e reduzindo as alíquotas de importação, além de iniciar o programa de privatizações (com o discurso de saldar a dívida pública), o pontapé inicial é dado. Entretanto, é com o Plano Real e a eleição de Fernando Henrique Cardoso para a presidência da República que o Brasil se submeterá de forma mais completa às exigências do Consenso de Washington. Naquele momento, o plano iria proporcionar a estabilidade de preços e, ao mesmo tempo, a intensificação da abertura econômica, com a valorização da moeda e o aumento da demanda.

De algum modo, essas medidas foram "antecipadas" com a chegada do grupo do CIC ao poder no Ceará, ainda em 1986. A implantação de algumas medidas corroborariam para uma maior fluidez do capital e, consequentemente, facilitariam o processo de abertura. Exemplo já mencionado foi o fato de Tasso ter promovido um enxugamento da máquina administrativa, medida semelhante que seria adotada por Collor em seu "Plano Collor I" (março de 1990).

Porém, é durante a década de 1990, sobretudo a partir do Pacto de Cooperação Cearense, iniciado com o Governo Ciro Gomes, que o Ceará acelera seu processo de abertura e uma maior incorporação da filosofia neoliberal. O Pacto pode ser compreendido como uma nova prática de planejamento estatal no nível do governo estadual (GUNN, 2004). Conforme Gunn (2004, p. 157), "o trabalho 'técnico' do governo submete-se agora, aparentemente, ao crivo do debate, análise e negociação de projetos nos encontros itinerantes, seminários e reuniões de trabalho do Pacto".

A partir daí e com o retorno de Tasso ao Governo do Estado, uma série de ações será efetivada, permitindo ao Ceará assumir um novo papel na divisão social e territorial do Brasil. Simultaneamente dar-se-á uma maior visibilidade à "sua reestruturação econômica com objetivos claros de inserir-se no circuito da produção e do consumo globalizados" (ELIAS, 2002, p. 11).

Os projetos basilares sobre os quais se assenta a reestruturação da economia cearense são, principalmente, os de modernização da produção agrícola; implantação de novas indústrias; investimentos no turismo litorâneo; expansão do comércio e dos serviços e construção de todo tipo de infraestrutura necessária para dar fluidez à produção e ao consumo.

Ao observarmos a conjuntura percebemos 0 caráter modernizante e neodesenvolvimentista (ABUEL-HAJ, 1997) do projeto mudancista, assentado sobre a filosofia neoliberal. Neste, o Estado, ao mesmo tempo em que reduz sua participação enquanto provedor de saúde, educação, saneamento básico investindo o mínimo exigido pelas agências de financiamento para conseguirem recursos, aplica em uma infraestrutura 
BESERRA, F. R. S. Reestruturação do Capital e Indústria Calçadista na Região...

considerável, lembrando, grosso modo, o modelo desenvolvimentista brasileiro dos anos 1950-60, quando o Estado era o grande condutor do que se chamaria, na teoria marxiana, "desenvolvimento das forças produtivas".

A partir de recorrentes leituras da dinâmica territorial cearense, também é possível apreender que no bojo das políticas adotadas para a interiorização dos investimentos, com a justificativa de reduzir as desigualdades, não é todo o território que é beneficiado, mas partes (ou fragmentos) dele. Entretanto, as novas estratégias político-econômicas são eficazes quando, mesmo agindo somente em partes do território cearense, conseguem integrar o Ceará numa nova economia de trocas nacionais e globais (PEREIRA JÚNIOR, 2005). Reagindo de maneira eficaz diante da gradativa falência dos programas regionais, o Estado (e até mesmo alguns municípios) se impôs solidamente na conquista de investimentos externos, desenvolvendo estratégias de financiamento e de benefícios fiscais.

\section{A REESTRUTURAÇÃO DO CAPITAL NO CEARÁ E A INDÚSTRIA CALÇADISTA NO CARIRI}

A Região do Cariri compreende porções dos estados da Paraíba, Pernambuco e Ceará. O que a define, a priori, é a presença da Chapada do Araripe, traço marcante da composição morfoestrutural dessa região (BARROS, 1964).

Nosso recorte é o da Região do Cariri cearense, localizada ao sul do território do Estado, sendo composta por oito municípios, segundo divisão proposta pelo IBGE (2000) em microrregiões ${ }^{4}$. Embora tenhamos escolhido este recorte, ressaltamos existirem outras propostas para a delimitação dessa região a partir de órgãos governamentais e centros de pesquisas.

É nesta região onde as transformações imanentes à fase mais recente da industrialização cearense, iniciada em meados dos anos 1980 (AMORA, 2005), terão maior intensidade a partir do ano de 1995, quando Tasso Jereissati volta ao governo do estado, sucedendo Ciro Gomes. Em seu segundo mandato Tasso traz consigo o "Programa de Promoção Industrial e Atração de Investimentos". O Programa objetivava desenvolver mecanismos para a divulgação de oportunidades de investimentos industriais através de incentivos fiscais e
Ao pensarmos em políticas para o turismo, grande parte será direcionada à áreas litorâneas. Olhando para os projetos de irrigação, a Região do Baixo Jaguaribe é a grande "beneficiada" no processo. Quanto à industrialização, grande parte da atividade está concentrada na Região Metropolitana de Fortaleza e, quando se dispersa pelo território, instala-se em lugares atrativos e estratégicos para seus investidores. É o caso de Sobral, onde a empresa calçadista Grendene se instala por conta de uma série de investimentos que recebe e por ter ali disponível uma mão de obra abundante e barata.

Semelhante é o caso da Região do Cariri, tradicional polo produtor calçadista desde fins do séc XIX e que vem, nas últimas décadas recebendo incentivos do governo. Voltaremos nosso olhar para a Região, buscando apreender o processo de industrialização no setor calçadista desde fins dos anos 1980 até os dias atuais, bem como analisando o espaço regional através das relações que o vem produzindo. financeiros, apoio tecnológico, mercado e infraestrutura de modo que induzisse empresários locais, nacionais e estrangeiros a realizarem investimentos no Estado.

Os incentivos fiscais seriam estabelecidos com base em renúncias diferenciadas de ICMS (podendo chegar até $75 \%$ ). Também estariam associados a estes incentivos aqueles oferecidos por mecanismos e programas de caráter regional para o Nordeste, merecendo destaque o Fundo de Investimentos do Nordeste (FINOR), o Fundo Constitucional de Financiamento do Nordeste (FNE) e o Fundo de Desenvolvimento Industrial (FDI-PROVIN), liberados para empresas que atendessem ao perfil exigido pelos Programas do Estado.

Para gerenciar este programa foi criada, no governo Lúcio Alcântara (2003), a Secretaria de Desenvolvimento Local e Regional (SDLR) com o objetivo de, ao criar escritórios regionais (oito ao total, estando um no Cariri), ampliar ainda mais a política de atração da média e grande empresa voltada para a exportação. Outros programas também contribuíram para a realização deste objetivo: o Programa Ceará Empreendedor, a organização de Arranjos Produtivos Locais, o Programa de

4 Divisão em microrregião geográfica, compreendendo a Região do Cariri os seguintes municípios: Barbalha, Crato, Jardim, Juazeiro do Norte, Missão Velha, Nova Olinda, Porteiras e Santana do Cariri. 
BESERRA, F. R. S. Reestruturação do Capital e Indústria Calçadista na Região...

Mini distritos Industriais, o Programa de Intermediação de Mão de Obra, o Programa de Apoio à Exportação, o Programa de Consolidação de Polos de Educação Superior e Tecnológica no Estado, bem como o fortalecimento da infraestrutura do território cearense.

A análise da distribuição dos investimentos para o Estado do Ceará, segundo os setores industriais, evidencia que foi o setor tradicional da indústria de transformação aquele que mais se destacou. $O$ valor total de investimentos realizados pelo Estado, segundo relatório da Secretaria de Desenvolvimento Econômico (2001), foi de $\mathrm{R} \$ 6.412 .834,58$ - o que equivale a 56,1 $\%$ dos investimentos provenientes do FDI-PROVIN distribuídos entre 348 empresas $(69,1 \%$ destas são indústrias calçadistas, têxtil e alimentícia). Em segundo lugar destaca-se o setor dinâmico da indústria (metalurgia, química e materiais elétricos), com $25,6 \%$ das empresas e $16,6 \%$ dos investimentos.

Os serviços industriais responsáveis pelo fornecimento de água, energia elétrica e gás, também se destacaram por apresentar uma taxa de crescimento média de $6,5 \%$ ao ano. Por fim situam-se os setores da construção civil e da extração mineral, a última apresentando taxas negativas entre os anos de 1995-2002.

Ao lado dos investimentos econômicos e incentivos fiscais também estaria a realização de estudos realizados pelas instituições estaduais para verificar a viabilidade de instalação de empreendimentos industriais em pontos estratégicos (grande capital e seu empresariado), bem como a capacitação de pessoal para uso como mão de obra.

Quesito importante no programa foi a interiorização da indústria através da instalação de novas plantas no interior do Estado, visando diminuir a concentração na RMF. Desse modo, o Estado elegeria algumas microrregiões para onde seriam canalizados investimentos maciços tornado-as aptas a receberem novas unidades industriais, agindo também no sentido de modernizar aquelas já existentes. Os incentivos e investimentos diretos para as empresas seriam ampliados à medida que buscassem localizar-se no interior do Estado.

Os órgãos governamentais diretamente envolvidos nesse Programa de Promoção Industrial e Atração de Investimentos seriam a SIC/CODITUR, responsáveis pela implementação, a SECITECE, SEARA e SEBRAE, apoiando os aspectos técnicos e SEFAZ/SEPLAN nos aspectos fiscais, em parceria com a iniciativa privada.

Segundo os dados do relatório emitido pelo Programa, até 2001 foi investido na região do Cariri o valor aproximado de $\mathrm{R} \$ 203.000 .000,00$, gerando 8.396 empregos diretos e 33.584 indiretos. Do total desse montante, aproximadamente $75 \%$ são recursos provenientes diretamente do Fundo de Desenvolvimento Industrial (FDI) que proporciona uma taxa de amortização em torno dos $25 \%$. Os incentivos, em sua maior parte, teriam a durabilidade de 15 anos.

Os dados revelaram ainda a origem dos investimentos, sendo a maioria proveniente das iniciativas locais, seguidos por investimentos originários de outros estados (São Paulo e Rio Grande do Sul). Quanto aos gêneros industriais foram os seguintes: metal-mecânico, papelaria, química, cerâmicas, móveis domésticos, a produção calçadista e seus subsidiários, totalizando 60 unidades industriais. Portanto, as empresas mais significativas e que absorveram maior contingente de mão de obra foram aquelas relacionadas à produção de bens de consumo ligados aos ramos tradicionais, a saber, as indústrias de calçados e confecções. O maior destaque foi para a empresa gaúcha Grendene, que se instalou em 1996, no Crato, ocupando, atualmente, 2347 empregados.

Em síntese, de um total de $\mathrm{R} \$ 203.447 .288,39$ investidos em 60 unidades industriais de diversos setores, coube ao setor calçadista uma fatia de $\mathrm{R} \$$ $75.840 .146,00$, isto é, $37 \%$ do total de recursos distribuídos entre empresas de origem local e a Grendene, única empresa de origem externa vinda do Rio Grande do Sul. Vale ressaltar que somente a Grendene foi beneficiada com $R \$ 25.000 .000,00$ enquanto $R \$$ 22.000.000,00 deveriam ser investidos numa empresa de origem local, a INPAS Comercial, o que não ocorreu. Excetuando-se essas duas, cerca de 18 empresas foram beneficiadas com o restante dos investimentos, ou seja, $\mathrm{R} \$ 28.840 .146,00$.

Participação importante também nesse processo têm desempenhado as prefeituras municipais de Crato, Juazeiro do Norte e Barbalha. Isto se deve ao fato da criação de Secretarias de Desenvolvimento Econômico, Comércio e Indústria na gestão que compreende o período de 2004 - 2008. A estas cabe o papel de coordenar o processo de atração e instalação de unidades industriais. Para tanto, as prefeituras negociam os terrenos, disponibilizam infraestrutura e autorizam isenções de impostos como forma de incentivos. A Prefeitura de Juazeiro do Norte mostra-se como uma das maiores interessadas em reativar o Distrito Industrial do Cariri, investindo em uma significativa infra-estrutura como, por exemplo, a construção do Anel Viário que ligará os três municípios cruzando o Distrito.

Outra ideia que também vem se desenvolvendo pelas administrações municipais é a de mini distritos, ou seja, pequenas concentrações industriais com infraestrutura montada pelas prefeituras e situadas em lugares estratégicos para o processo de produção. Estes mini 
BESERRA, F. R. S. Reestruturação do Capital e Indústria Calçadista na Região...

distritos são localizados perto das rodovias que cortem os municípios e do futuro Anel Viário.

Ao observar os dados mais recentes, verificamos que, no ano de 2006, a Região contava com 110 indústrias no setor calçadista ${ }^{5}$ concentradas nos três municípios acima citados. Destas, 100 localizavam-se no município de Juazeiro do Norte, enquanto que em Barbalha estavam instaladas 8 unidades e, no município do Crato, apenas duas.

Estas 110 indústrias podem ser classificadas de acordo com o número de empregados. São 24 as que possuem o um número maior que 100 trabalhadores, 69 as que possuem entre 10 e 99 trabalhadores e 17 as que possuem entre 5 e 9 trabalhadores.

Deste universo, foram selecionadas 20 unidades para realizarmos a aplicação de questionários, tendo em vista o número de empregados e o volume da produção. Com base nesses critérios estabeleceu-se a seguinte amostragem:

- Os maiores estabelecimentos industriais ocupando acima de 100 empregados, o que correspondeu a 10 unidades;

- Estabelecimentos industriais contendo entre 10 e 100 empregados, correspondendo a 10 unidades.

Tanto em um como em outro o volume da produção foi proporcional ao pessoal ocupado.

Para o primeiro grupo de empresas temos o seguinte perfil: em sua maioria têm mais de dez anos e sua origem se deu diretamente na produção de calçados ou foi gerada a partir da comercialização de alguma das matérias-primas utilizadas para a confecção dos calçados ou dos calçados propriamente ditos. A produção está voltada principalmente para calçados femininos feitos em couro ou materiais sintéticos. A matéria-prima é originária de diversos lugares: os materiais sintéticos são comprados principalmente em São Paulo, Bahia e Rio Grandes do Sul. As embalagens, Bahia, Rio Grande do Norte e Pernambuco. O material reciclável é fornecido principalmente pelo Rio Grande do Norte, mas também é comprado no Ceará e em Recife. Algumas que ainda trabalham com o couro cru o adquirem no próprio Juazeiro do Norte, no curtume Santo Agostinho, único da Região e existente há mais de 36 anos.

A capacidade de produção destas empresas varia entre 20.000 - 100.000 pares de calçados/dia. Entretanto, nenhuma delas produz em sua capacidade total, girando a produção em torno de $50-70 \%$ do total possível. O número de empregados por empresa varia entre 100 e 850 trabalhadores. O maquinário utilizado para dar conta da produção é, em sua maioria, importado da China, embora algumas empresas utilizem máquinas brasileiras. Quando interrogados sobre a manutenção destas máquinas, todos responderam que alguns funcionários foram treinados pelos revendedores para atuarem no conserto das máquinas. Quando é necessário desmontar por completo alguma máquina, aciona-se uma assistência técnica especializada.

A produção deste primeiro grupo é vendida para os mais diferentes lugares. Ponto comum é que todas as empresas alcançam todo o território nacional, embora aleguem que há dificuldade na distribuição, por conta do custo de transportes, sobretudo para a Região Norte. As que extrapolam o mercado interno alcançam países da América do Sul, Central e do Norte, bem como al-

\begin{tabular}{|c|c|c|}
\hline & $1^{\circ}$ Grupo de Indústrias Pesquisadas & $2^{\circ}$ Grupo de Indústrias Pesquisadas \\
\hline Origem & Local & Local \\
\hline Tempo de atividade & 10 anos ou mais & No máximo 10 anos \\
\hline Matéria-prima utilizada & Couro e sintéticos & Sintéticos \\
\hline Quantidade de Mão de obra empregada & $>100$ trabalhadores(as) & $<100$ trabalhadores(as) \\
\hline Maquinário utilizado & $\begin{array}{l}\text { Importados da China e uma } \\
\text { pequena quantidade de nacionais }\end{array}$ & Eminentemente nacional e local \\
\hline Capacidade de produção & Até 100.000 pares de calçados/dia & Até 20.00 pares de calçados/mês \\
\hline Mercado Consumidor & $\begin{array}{l}\text { Brasil, outros países da } \\
\text { América do Sul; América Cen- } \\
\text { tral e do Norte; Europa. }\end{array}$ & $\begin{array}{l}\text { Território Nacional, sobretudo } \\
\text { Regiões Norte e Nordeste }\end{array}$ \\
\hline Incentivos para a produção & Municipal, estadual e federal & Não disponibilizam \\
\hline
\end{tabular}

QUADRO 1 - SÍNTESE COMPARATIVA ENTRE OS GRUPOS DE INDÚSTRIAS PESQUISADOS

5 Gostaríamos de reforçar o fato que aqui estamos tratando apenas das indústrias que possuem razão social. Segundo o SINDINDÚSTRIA e AFABRICAL, no total, existem mais de 300 empresas no município, porém, sem registro formal. 
guns países da Europa. É relevante perceber a relação com o mercado externo, que não é somente de venda da produção. Algumas dessas empresas dispõem de pessoal especializado no design dos calçados que viajam periodicamente para os centros da moda a fim de estarem a par das últimas tendências. Caso excepcional de uma empresa que nos relatou manter uma parceria com uma empresa de design europeia que the repassa diretamente os modelos a serem fabricados.

Outra característica importante é a origem dos recursos utilizados pelas indústrias. Todas as unidades visitadas têm capital de origem local. Isso nos leva a refletir sobre a capacidade do acúmulo de capital por um grupo local, ou seja, uma burguesia industrial. Essas indústrias também dispõem de algum tipo de incentivo ou recurso das diferentes esferas governamentais; municipal (infraestrutura); estadual, via FDI; federal, via SUDENE.

No segundo grupo de indústrias visitadas, que constituem as unidades com menos de 100 empregados, os resultados diferem em alguns aspectos. A maioria dessas unidades são recentes, possuindo, no máximo, dez anos de existência. Tiveram origem como produtoras de calçados, já utilizando como matéria-prima principal os sintéticos. Grande parte produz calçados femininos, excetuando-se uma, que produz sapatos mocassim masculinos. A obtenção da matéria-prima segue o mesmo percurso do grupo anterior, ou seja, a maioria é proveniente das regiões Sul e Sudeste do país.

A capacidade de produção é bastante inferior, alcançado 20.000 pares de calçados/mês. Também nenhuma delas produz em sua capacidade total, girando a produção em torno de $50-70 \%$ do total possível. O maquinário utilizado para dar conta da produção é todo fabricado no território nacional. Juazeiro do Norte conta com uma empresa que produz este maquinário.

O mercado consumidor dos produtos destas indústrias também é nacional e, sobretudo, nordestino. Algumas realizaram vendas para outros países, mas em transações estanques, não tendo continuidade. São poucas as empresas que mantêm um grupo de pessoas envolvido com o desenvolvimento de designer para seus produtos.

A origem dos capitais dessas empresas também é local. O que as diferencia do primeiro grupo é o fato de não utilizarem nenhum recurso ou investimento do setor público. Os recursos até existem, mas as empresas não atendem os requisitos exigidos como formas de garantia pelo governo.

\section{O CARIRI CEARENSE: A SÍNTESE DAS MÚLTIPLAS DETERMINAÇÕES}

A partir dos dados supracitados, é possível fazermos uma leitura da Região caririense sob a perspectiva da indústria calçadista e perceber, novamente, alteração em sua configuração territorial. Agora podemos entender a indústria de calçados do Cariri como uma acumulação de tempos no espaço, de acordo com Santos (2004). Esta indústria é composta por: 1) unidades artesanais, onde se mantém a tradição da produção calçadista do couro remetida ao início do século XX e que conserva a maioria de suas características; 2) unidades fabris pequenas e médias, possuidoras de uma produção dita "moderna" e concentradas na confecção de produtos sintéticos e, por fim; 3) a Grendene, uma empresa isolada do contexto histórico Caririense, que chega ao Cariri por meio dos programas de atração industrial, patrocinados pelo governo estadual.

O primeiro grupo ainda guarda uma identificação com a origem, a história e a cultura do lugar. Sua produção é comercializada, sobretudo no local, embora também existam algumas unidades que vendem calçados para São Paulo e outros estados mais próximos do Ceará. A maioria dos produtos é do tipo sandálias de rabicho, a priori produzidas de modo artesanal e, hoje, com a produção fabril, tomou o formato das já conhecidas sandálias "havaianas". A produção se desenvolve nas residências dos trabalhadores, em pequenas oficinas, ou em pequenas lojas no centro da cidade, onde a produção e a comercialização realizamse concomitantemente. São poucos os que possuem registro formal.

O segundo grupo, o das pequenas e médias empresas têm sua produção voltada principalmente para os derivados sintéticos, na linha de sandálias microporosas e placas de borracha de Etil-Vinil-Acetato (EVA). Com o avanço da produção o Cariri torna-se, nos dias atuais, o maior produtor de EVA do Brasil, contando com nove empresas no segmento (AMARAL FILHO; SOUZA, 2003).

Os calçados fabricados por estas unidades são predominantemente femininos, porém, com uma parcela pequena, algo em torno de $13 \%$, destinada aos calçados infantis. Apresentam como características principais o solado de Policloreto de vinila (PVC) e o cabedal de couro sintético. O principal componente produzido na região é o injetado, de EVA, PVC e PU (Poliuretano). 
BESERRA, F. R. S. Reestruturação do Capital e Indústria Calçadista na Região...

Alguns autores, sobretudo aqueles mais afeitos ao discurso mudancista, têm procurado dar à dimensão da produção calçadista do Cariri a noção de um Arranjo Produtivo Local (APL). Entretanto, uma das características fundamentais para a compreensão de um arranjo é a necessidade que têm seus agentes de manter interações entre si constantemente, estabelecendo padrões de comportamento (ALBAGLI; BRITO, 2003). Em nossas visitas de campo, percorrendo as indústrias e discutindo com os atores responsáveis pelo processo, nas mais diferentes esferas, não encontramos elementos que nos levassem a concordar com a existência de um Arranjo Produtivo Local no setor calçadista no Cariri. No questionário uma das perguntas estava diretamente relacionada ao APL. Ao interrogarmos determinada empresa sobre sua existência e participação a resposta, por parte de empresários e diretores, foi unânime ao afirmarem não haver tal arranjo, alguns mesmo até desconhecendo o seu significado.

Em nossa leitura acreditamos que o conceito de sistema industrial localizado desenvolvido por Reis (1988, apud SCHNEIDER, 2004) é muito mais próximo de um esforço de teorização acerca da produção calçadista caririense. Segundo Reis, pode ser definido como:

[...] um espaço de produção característico das formas de desenvolvimento intermédio e não metropolitano definido simultaneamente por: a) condições industriais próprias; b) formas de representação coletiva; c) condições sócio-econômicas e territoriais relacionadas com os modos de reprodução social predominantes (REIS, apud SCHNEIDER, 2004, p. 55).

Compreendemos que este sistema não ocorre em qualquer lugar, seu modelo de desenvolvimento aparece nos lugares onde há uma forte densidade populacional ativa e uma densa e crescente rede urbana. São também lugares onde historicamente se tem uma intensa tradição artesanal a qual, de alguma forma, permitiu o desenvolvimento ao pleno exercício da indústria baseada em iniciativas predominantemente locais e com interações fortes entre a economia e a sociedade.

É necessário afirmar que esta não é uma definição única e consensual sobre os sistemas industriais localizados. A rigor, o fenômeno do desenvolvimento industrial local não é igual nas várias regiões onde possa ocorrer. Entretanto, é possível certificar que tais sistemas produtivos operam com base em relações de trabalho e de produção peculiares que estão diretamente relacionados com a formação socioeconômica específica de cada lugar. A essa formação, organizada sobre uma base territorial, é possível chamar de formação regional.

Por fim, a Grendene. Instalada no município do Crato em 1996, migra para o Nordeste ${ }^{6}$ devido à estratégia de recuperação de competitividade, afetada pela a abertura comercial brasileira (anos 1990) e o fortalecimento de mercados externos. Os principais fatores que atraíram a empresa para o Estado foram: os incentivos fiscais oferecidos pelo governo estadual; a mão de obra barata, abundante e desorganizada sindicalmente; e a proximidade com o mercado externo. A empresa também contou com a disponibilização do terreno e treinamento de mão de obra, realizado em convênio com a Companhia de Desenvolvimento do Ceará (CODEC). Na esfera municipal, a Grendene contou com a concessão de incentivos sobre o IPTU. Além disso, obteve financiamentos junto ao BNDES e FNE-BNB.

Para a realização da produção, a Grendene mobiliza 2.347 trabalhadores (dados de 2006), todos em regime de CLT, com escolaridade variando entre os níveis de ensino fundamental e médio para o pessoal de chão de fábrica. Isso responde por algo em torno de um terço do total de empregos diretos gerados no município do Crato. Segundo Amaral Filho e Souza (2003), os gastos com mão de obra têm representado $21 \%$ dos gastos totais, o suficiente para provocar impactos consideráveis na economia local do município, atuando diretamente no volume das vendas locais de bens de consumo, duráveis e não duráveis. Os níveis salariais dos empregados de chão de fábrica giram em torno de um salário mínimo.

Cabe ressaltar que, embora a unidade da Grendene instalada no Crato não seja tão expressiva quanto ao número de empregados, como a que está em funcionamento no município de Sobral, empregando em determinados momentos do ano mais de 10.000 trabalhadores, ela tem uma importância fundamental para o grupo Grendene no Ceará. Além dos calçados ela produz todo o EVA que é distribuído para as demais unidades no Estado.

A empresa não mantém suas atividades de pesquisa e desenvolvimento no Ceará, uma vez que esta etapa do processo permanece localizada no Rio Grande

6 Além do município de Crato, a Grendene ainda possui duas outras unidades no Ceará: em Sobral, onde emprega mais de 9.000 trabalhadores e em Fortaleza. 
BESERRA, F. R. S. Reestruturação do Capital e Indústria Calçadista na Região...

do Sul, bem como seus departamentos de Marketing, vendas e contabilidade. De semelhante modo, a diretoria permanece naquela região.

Os insumos da empresa não são comprados no Cariri. Entretanto, o Ceará participa com 30\% da compra desses insumos enquanto $70 \%$ são adquiridos em outros estados da federação como: Paraíba, Bahia, Rio de Janeiro e São Paulo. Os insumos comprados no Ceará são: pigmentos, carbonato de cálcio e caixas coletivas. Embora possa produzir efeitos "para frente" no setor calçadista, uma vez que aproxima as pequenas e médias empresas das inovações relativas aos produtos e ao processo produtivo, a referida indústria não promove nenhum efeito "para trás", no tocante à compra de insumos.

Como já afirmamos anteriormente, a Grendene é uma empresa que, no setor calçadista, encontra-se em uma posição isolada no Cariri. Isso porque sua lógica foge àquela que descrevemos acima das demais indústrias de calçados da Região. A chegada da Grendene ao Cariri exige uma explicação que aponta para a transferência de diversas indústrias do setor de bens de consumo não duráveis das Regiões Sul e Sudeste do país para o Nordeste, sobretudo para o Ceará, como problematizado em Moreira (2004), ao discutir a nova divisão territorial do trabalho no Brasil.

Estas transferências, por sua vez, se relacionam a uma série de fatores que iniciados no fim dos anos 1980, agudizam-se na década de 1990. Um destes fatores é a implementação de uma vigorosa política de abertura externa, expandindo o grau de abertura da economia nacional e permitindo crescer as exportações e importações. Diante desta conjuntura, as empresas precisam reestruturar-se para manter-se no cenário competitivo do mercado e continuarem sua reprodução ampliada.

Essa reestruturação dar-se-á em pelo menos dois aspectos. No âmbito da produção, isto é, a inserção de novas tecnologias associadas à organização flexível do processo produtivo. O segundo é a dinâmica territorial que estas empresas adquirem na busca de lugares onde as melhores condições sejam proporcionadas para sua produtividade crescente.

Embora a Grendene incorpore algumas das características da chamada acumulação flexível, é uma indústria intensiva em mão de obra, que conserva ainda a esteira em seu processo de produção. Portanto, a reestruturação espacial, ou seja, a migração das unidades de produção da empresa para o Ceará, atua como fator de maior relevância.

A este movimento do capital na busca de expandir-se para áreas consideradas propícias a expansão dos seus superlucros, Santos (2004) denomina de seletividade espacial. Esta seletividade não se dá por qualquer espaço, mas por aqueles em que se desenvolve determinada atividade ou um conjunto de atividades que possibilitem rentabilizar sua produção. Esta seletividade ocorreria ainda em virtude das condições locais de ordem técnica e organizacional, produzindo uma eficácia mercantil.

À ideia de seletividade espacial se associa a de ajuste espacial (HARVEY, 2005). Segundo este autor, por ajuste espacial é possível entender a exportação dos excedentes de força de trabalho e capital como meio de evitar a desvalorização do capital. Com a necessidade do capital de produzir, contínua e aceleradamente, novos recursos produtivos, surge também a necessidade de criar um mercado mundial. A função desse mercado é intensificar o volume de trocas para produzir novas necessidades e novos tipos de produtos "para implantar novos recursos produtivos em novas regiões, e para colocar toda a mão de obra sob a dominação do capital" (HARVEY, 2005, p. 117). Ainda conforme o pensamento do autor, é por intermédio de mudanças e reestruturações geográficas que existem todos os tipos de possibilidades para protelar as crises, sustentar a acumulação e modificar a luta de classes.

Portanto, ao pensarmos a Grendene no quadro regional caririense, é preciso compreendê-la dentro de um processo de reestruturação que vem ocorrendo no país (e no mundo), promovendo uma nova divisão do trabalho no Brasil que não ocorre de forma aleatória, mas que define muito bem os lugares a serem selecionados para a sua efetivação.

A indústria calçadista do Cariri ultrapassa o contexto estadual e a Região é reconhecida como importante polo produtor no país. Em entrevista com representantes da FIEC obtivemos dados que colocam o Cariri cearense como o $5^{\circ}$ maior produtor em volume de pares de calçados do Brasil e como o $1^{\circ}$ produtor em número de pares de sandálias. $O$ grande momento para a exposição desse polo é a Feira de Tecnologia e Calçados do Cariri (FETECC), que ocorre anualmente e para onde convergem empresários calçadistas de todas as partes do país.

Essa lógica de polo produtor de bens não duráveis no contexto nacional não é peculiaridade da Região do Cariri. Em Fortaleza o polo têxtil e de confecções também é tradicionalmente um dos mais importantes centros no setor, tanto em âmbito regional como nacional (ARAÚJO, 2000).

O desenvolvimento da Região enquanto polo produtor calçadista não pode ser apreendido nos moldes tradicionais da passagem da manufatura à grande indústria, o que seria um reducionismo. O que ocorre é 
BESERRA, F. R. S. Reestruturação do Capital e Indústria Calçadista na Região...

que, com a crise de lucratividade e produtividade dos setores industriais, o setor calçadista se insere no movimento da concorrência mediada pela reestruturação capitalista.

A partir do acima exposto é possível então, neste momento, traçar algumas características que peculiarizam o processo de industrialização no Ceará, bem como na Região do Cariri. A primeira diz respeito ao desenvolvimento da indústria cearense, que ocorreu fortemente atrelada à presença de atividades agropecuárias (o algodão e o couro), bem como a uma agricultura de subsistência que mais tarde permitira o desenvolvimento da indústria alimentícia (sobretudo castanha de caju, óleos vegetais, frutas tropicais). Em consequência disso grande parte do parque industrial do Ceará é hoje formado por indústrias ligadas aos setores de bens de consumo não duráveis.

A segunda característica é decorrente da primeira. Ao refletirmos o desenvolvimento desse complexo ligado ao gado e ao algodão e sua consequente industrialização, buscamos identificar seus atores. Em nossa leitura, grande parte da burguesia industrial hoje existente no Estado do Ceará é proveniente de uma antiga oligarquia sertaneja que se expandiu a partir da acumulação comercial. Alguns desse atores se definem muito claramente. Na Região do Cariri, por exemplo, um caso clássico é o da família Bezerra de Menezes (LEMENHE, 1995). Alguns industriais por nós identificados antes desenvolviam algumas atividades ligadas à agricultura ou ao comércio e depois partiram para o setor industrial. A representação deste grupo, hoje, ocorre principalmente por meio do Sindicato das Indústrias de Calçados e Vestuário de Juazeiro e Região (SINDINDÚSTRIA), cujo principal objetivo é a divulgação da produção caririense e da captação de novas tecnologias para as indústrias.

Em síntese, é possível pensar essa seletividade espacial no território cearense, capturados pelo ajuste espacial da produção capitalista. Estes espaços, que já dispunham de certa tradição, possuidores de determinadas estruturas, foram dinamizados com a modernização das indústrias, modernização que se deu pari passu à chegada de novos estabelecimentos industriais. Longe de exprimirem territorialidades em oposição ou em disputas, estas formações são complementares e parecem estar, de certa forma, bem definidas no Estado, a saber, na Região Metropolitana de Fortaleza, e nas cidades médias do interior do Estado, ou seja, Crato, Juazeiro do Norte e Barbalha, que compõem a Região do Cariri, e Sobral, na porção Norte cearense.

De acordo com Castells (2002), estes lugares não estão individualizados em seus processos, porém inter- conectados espacialmente, de forma a complementar as tendências contraditórias derivadas de conflitos e as estratégias entre atores sociais que representam interesses e valores opostos. Essa interconexão se dá por meio dos fluxos, que constituem "uma nova forma espacial característica das práticas sociais que dominam e moldam a sociedade em rede" (CASTELLS, 2002, p. 501). Estes fluxos são sequências intencionais de interação entre posições fisicamente desarticuladas nas estruturas econômica, política e simbólica da sociedade.

Castells nos apresenta este espaço de fluxos considerando que o mesmo pode ser descrito pela combinação de pelo menos três camadas de suportes matérias que, juntas, constituem o espaço de fluxos: a primeira é formada por um circuito de impulsos eletrônicos, formando, em conjunto, a base material dos processos estrategicamente cruciais na rede da sociedade; a segunda camada são os nós, centros de importantes funções estratégicas e centros de comunicação (esses nós são materializados no lugar); por fim, a terceira camada, a organização espacial das elites gerenciais dominantes. Em nosso entendimento, compreenderíamos essas camadas como sendo, a primeira, o conjunto que permite interligar os diferentes nós, isto é, as redes de telecomunicações e de transportes. A segunda, os nós, seriam exatamente os lugares que participariam, de algum modo e em diferenciados graus, do processo produtivo. A terceira seriam as classes dominantes (embora o próprio Castells não o admita como tal), aquelas que controlam o processo nas esferas local e global.

Ao nos determos sobre a aglomeração urbana do CRAJUBAR, isto é, ao aglomerado formado pelos municípios de Crato, Juazeiro do Norte e Barbalha, observamos uma série de novidades, isto é, Sistemas de Objetos e Sistemas de Ações, na expressão de Santos (2004), que se inserem no lugar e que viabilizam as condições necessárias para que se reproduzam as verticalidades e horizontalidades que efetivam a adaptação do Cariri como lugar do mundo.

Como exemplos podemos citar: a reforma do aeroporto regional, situado em Juazeiro do Norte; a meIhoria da infraestrutura básica nos lugares privilegiados para a instalação de novos empreendimentos, como a Avenida Padre Cícero, que liga Juazeiro do Norte a Crato e da Avenida Leão Sampaio, que liga Juazeiro do Norte à Barbalha. $\mathrm{O}$ acesso aos referentes municípios também se intensifica, tanto na escala local, com o desenvolvimento de um sistema de ônibus urbanos, de transportes alternativos como vans e moto-táxi, como em escala regional e nacional, da rodoviária de Juazeiro do Norte é possível alcançar diversos lugares do Brasil. 
BESERRA, F. R. S. Reestruturação do Capital e Indústria Calçadista na Região...

Outra característica é a instalação de órgãos estaduais e federais, além de outros para atendimento à Região como um todo, sendo Juazeiro do Norte o centro de convergência. Também é perceptível na região os signos da moderna sociedade de consumo, como o "Cariri shopping", redes de supermercados e, mais recentemente, a construção de prédios residenciais superiores a 10 andares.

O desenvolvimento da indústria do Cariri, bem como de suas atividades de comércio e serviço, concentram um número relativo de pessoas na região bem como uma quantia considerável de capital. Consequentemente, o espaço é apropriado privativamente como condição geral de produção, enquanto a população socializa as desvantagens criadas pelo seu desenvolvimento (CARLOS, 1994).

$\mathrm{Na}$ medida em que ocorre a modernização de uma parcela do espaço na busca de atender a um grupo de atores hegemônicos em suas necessidades de apropriação e reprodução, uma outra parcela do território está à parte, excluída das benesses oferecidas pela modernização, abrigando um outro grupo de atores, os hegemonizados.

O processo de modernização é seletivo, conservador, gerando exclusão e marginalização. Isso se reflete, por exemplo, no fato de que nos municípios aqui abordados existem zonas restritas que abrigam bairros com um considerável padrão arquitetônico nas residências. Lugares que contêm equipamentos e infraestruturas modernas e, de modo semelhante, possuem zonas onde a favelização e a pobreza são notórias, percebendo-se a inexistência de infraestrutura adequada para habitação.

Outro exemplo é o desenvolvimento desigual dos próprios municípios que, embora submetidos a uma mesma lógica de incentivo e desenvolvimento, responderam diferentemente a este processo, mostrando a Região do Cariri como um mosaico no processo de reestruturação produtiva do capital. Barbalha dá continuidade a uma lógica agroindustrial e, dos três municípios é aquele que apresenta um ritmo de desenvolvimento mais lento. Crato e Juazeiro do Norte apresentam maior absorção de investimentos voltados para a indústria, embora o setor de serviços seja o de maior significação para a região. No conjunto, parece ser Juazeiro do Norte aquele que desponta como "maior beneficiado" do processo.

Consequente a isso, podemos perceber a industrialização como responsável também por importantes transformações na organização do espaço urbano, na medida em que expressa crescimento econômico e redistribui uma gama de atividades, remetendo às cidades novas formas e dimensões, bem como a materialização de novos objetos e movimentos na economia espacial do CRAJUBAR.

\section{CONSIDERAÇÕES FINAIS}

O espaço caririense enquanto totalidade revelase como produto e condição de suas práticas sociais. Enquanto fração desta totalidade, um lugar na lógica do desenvolvimento e da reestruturação do sistema capitalista que paulatinamente se submete aos seus ditames.

Ao pensarmos a industrialização da produção calçadista no Cariri é possível observar essa dupla dinâmica: se de um lado novos elementos chegam objetivando modernizar a produção e acelerar seu ciclo de reprodução, de outro, vai buscar naquilo que há de mais tradicional no lugar, isto é, no calçado, no couro, no artesão, as bases para sua efetivação. Deste modo se redefine uma série de componentes - políticos, econômicos e culturais - que agora estarão pautados em uma lógica racionalista e evidenciarão o processo de reestruturação existente no lugar.

Entretanto, o lugar, ao ser submetido a esta nova lógica, o faz não sem resistência. E nesse processo onde um complexo de relações se desenvolve a reestruturação ao se materializar, não se materializa da mesma forma que em outros lugares. Como diria Santos (2005), muda o mundo e, ao mesmo tempo, muda o lugar. Mas é pelo lugar que o mundo é percebido empiricamente, isso porque nele convivem, dialeticamente, uma razão que é global e outra que é local.

Essa reestruturação também se materializa em sua forma espacial. Embora a paisagem do Cariri não se assemelhe à das clássicas cidades industriais, com suas chaminés, vastos galpões, grandes armazéns e máquinas de funcionamento ininterrupto, a produção do seu espaço vai revelando uma organização espacial que vem modificando as antigas formas de ocupação e apropriação. Esta organização se dá em uma trama de articulações que busca dar conta da produção em grande escala, dos empregados, da distribuição da população e da concentração de capital em parcelas do espaço.

As cidades do Crato, Juazeiro do Norte e Barbalha cada vez mais vão aparecendo como o lócus dinâmico de atividades e de pessoas. Nelas as edificações vão adensando-se cada vez mais, estáticas e diferenciadas. Um aglomerado que busca acelerar o tempo e reduzir as distâncias entre produção e consumo. 
BESERRA, F. R. S. Reestruturação do Capital e Indústria Calçadista na Região...

A apropriação do espaço vai ocorrendo cada vez mais de forma desigual e combinada. A disparidade será apresentada, por exemplo, na habitação: as mais ricas, localizadas em terrenos mais caros, com melhor infraestrutura, construídas em padrões arquitetônicos planejados; as mais pobres, localizadas nos cantos mais ermos, onde a infraestrutura é precária ou inexistente. Se de um lado surgem residências mais portentosas do ponto de vista da forma, do outro surgem as favelas densas do ponto de vista da vida.

O espaço vai sendo apropriado de forma diversa, por meio de uma sociedade que se divide em classes e que utiliza fragmentos desse espaço com fins produtivos ou improdutivos, mas que não o faz sem luta. Esta luta vai fazendo dos homens e mulheres que trabalham nas indústrias de calçados do Cariri, quer artesãos, quer operários ou como queiram defini-los, produtores de sua existência, de sua humanidade.

\section{REFERÊNCIAS}

ABU-El-HAJ, Jawdat. Neodesenvolvimentismo no Ceará: autonomia empresarial e política industrial. Revista Econômica do Nordeste, v. 25, n. 3, Fortaleza: BNB, p. 327-345, 1997.

ALBAGLI, S.; BRITO, J. Glossário de arranjos e sistemas produtivos locais e inovativos. Rede de Pesquisa em Sistemas Produtivos e Inovativos Locais (REDESIST). Rio de Janeiro: 2003. 56p.

AMARAL FILHO, Jair do; SOUZA, Dayane Lima Rabelo de. Arranjo produtivo de calçados do Cariri, Ceará. Fortaleza: SEPLAN/IPECE, 2003. 22p.

AMORA, Zenilde Baima. Indústria e Espaço no Ceará. IN: BORZACCHIELLO, José; CAVALCANTE, Tércia; DANTAS, Eustógio. (Orgs.). Ceará: um novo olhar geográfico. Fortaleza: Demócrito Rocha, 2005.

ARAÚJO, Tânia Bacelar. Ensaios sobre o desenvolvimento do Nordeste brasileiro: heranças e urgências. Rio de Janeiro: Revan: Fase, 2000. 390p.

BARROS, Haidine da Silva. O Cariri cearense: o quadro agrário e a vida urbana. Revista Brasileira de Geografia, Rio de Janeiro: IBGE, ano XXVI, n. 4, out.-dez. 1964.

CARLOS, Ana Fani A. A (Re)produção do espaço urbano. São Paulo: Edusp, 1994. 270p.

CASTELLS, Manuel. A Sociedade em Rede. 6. ed. São Paulo: Paz e Terra, 2002. (A era da informação: economia, sociedade e cultura, v. 1). 698p.

DRUCK, Maria da Graça. Terceirização: (des)fordizando a fábrica: um estudo do complexo petroquímico. São Paulo: Boitempo: Salvador: EDUFBA, 1999. 272p.

ELIAS, Denise. Integração competitiva do semi-árido cearense. IN: ELIAS, Denise; FURTADO, José Levi. (Orgs.). Modernização excludente. Fortaleza: Demócrito Rocha, 2002. p. 12-38.
GUNN, Philip. A Mídia na guerra dos lugares. In: DEÁK, Csaba; SCHIFFER, Sueli Ramos (Orgs.). O processo de urbanização do Brasil. São Paulo: EDUSP, 2004. p. 145-168.

HARVEY, David. Condição Pós-Moderna. 11. ed. São Paulo: Loyola, 2002. 349p.

A produção capitalista do espaço. São Paulo: Annablume, 2005. (Coleção Geografia e Adjacências). $251 \mathrm{p}$.

IBGE. Censo Demográfico 2000. Rio de Janeiro: IBGE, 2001.

MOREIRA, Ruy. A nova divisão territorial do trabalho e as tendências da configuração do espaço brasileiro. IN: LIMONAD, Ester et al. (Orgs.). Brasil, século XXI - por uma nova regionalização? Processos, escalas e agentes. São Paulo: Max Limonad, 2004.

LEMENHE, Maria Auxiliadora. Família, tradição e poder: o(caso) dos coronéis. São Paulo: Annablume, EUFC, 1995.

PEREIRA JÚNIOR, Edílson. Industrialização e reestruturação do espaço metropolitano: reflexões sobre o caso de HorizontePacajus (CE). Fortaleza: Eduece, 2005. 239p.

SANTOS, Milton. A natureza do espaço: técnica e tempo, razão e emoção. 4. ed. São Paulo: EDUSP, 2004. 384p.

$170 \mathrm{p}$.

. Da totalidade ao lugar. São Paulo: EDUSP, 2005.

SCHNEIDER, Sergio. Agricultura familiar e industrialização: pluriatividade e descentralização no Rio Grande do Sul. 2. ed. Porto Alegre: Ed. UFRGS, 2004. 220p.

TEIXEIRA, Francisco José Soares. A "razão esclarecida" da FIEC. In: Propostas Alternativas. Fortaleza: IMOPEC-ADUFC - CUT - CPT - CE, 1995. 24p. 
